\title{
Impact of Self-Fulfilling Prophecies on Progress and Motivation in Fosbury-Flop
}

\author{
Corinne Fantoni, Lou Counil, Marc Testa and Luc Collard \\ Department of Sports Science and Physical Education, University of Paris Descartes, 1 rue Lacretelle 75015 Paris, France
}

\begin{abstract}
In high jump, the determination of a student's theoretical best performance helps the elaboration of the PE teacher's early expectations. By affecting the student's motivation profile, knowledge of these expectations will have an impact on his progress. The study focuses on two ninth grade classes, where both are presented with a contest, a test and a questionnaire at the beginning and at the end of the cycle. We determine their actual and theoretical performances as well as their initial and final levels of self-determination. Only one class has been given knowledge of their theoretical performance. Then, two variables are analyzed: the "learning" variable linked to the duration of the cycle, and the "pedagogic modality" variable, whether the student is aware of his theoretical performance or not. The ANOVA (analysis of variance) tests performed have showed no significant impact of these variables on the performance, but their interaction is an important factor over the perceived progress. This significance is also observable on our subjects self-determination levels, intrinsic motivation and their overall skills. By fostering the teacher's perception, knowledge of the theoretical performance does not affect directly the student's performance but heightens his intrinsic motivation and favors the progress in his skills.
\end{abstract}

Key words: Motivation, expectations, self-fulfilling prophecies, performance, high jump.

\section{Introduction}

Apprehending failure while engaged in physical activity may slow down a student's progression. In an activity such as high jump, a student may be confronted to heights he never reached before: he will only be able to engage in the action, if he thinks himself capable of succeeding. The teacher will then have to target the heights that are likely to be reached by the student. The efficiency of his instruction will depend on the reliability of the selected indicators.

Using an equation of multiple regressions allows us to calculate the theoretical high jump performance of a student and therefore better answer his needs. The comparison between the real achievement and the theoretical achievement highlights the high jumpers' skill levels, which aims to "maximize the probability of success and minimize all costs" [1].

Indeed, the student who will achieve a performance that is equal to his theoretical performance, will then

Corresponding author: Lou Counil, Ph.D., research field: self-fulfilling prophecies and game. have reached the skill level requested for his form. Moreover, asking the student to make these calculations helps him identify a precise aim in his achievement and allows the teacher to create homogeneous groups.

The use of this theoretical tool participates in the elaboration of a rational assessment that is both diagnostic and final for Fosbury-flop. The teacher then has precise expectations concerning the student, whose reaction might be variable following the type of expectation. It may be positive, that is to say enhancive, or else negative and at variance with the perception of the student's skills. Neutral expectations might be interpreted in a negative way by the student. There is then a risk of harming his self-confidence and his self-esteem.

Numerous questions arise but we will only retain the following: (1) If the gap between the teacher's expectations and the student's own perception is too wide, what will be the impact on the student's motivation? (2) Moreover, will the teacher behave in 
the same way with the students with high theoretical skills and those whose physical capacities seem more limited?

We have focused our work on investigating the influence of a teacher's precise skill expectations, conveyed in this case by a calculation of the theoretical Fosbury-flop performance that sends us back to the concept of self-fulfilling prophecies concerning both the student's motivation and his progress.

\subsection{Motivation and Self-Determination Rating}

For the first generation of behaviorists [2-4], motivation designates the influence of a variety of physiologic states such as hunger, thirst, sexuality, sleep, need of oxygen, etc., on one's behavior.

The first theories related to the concept of motivation compared it to a force allowing the organism to go from a state of rest to a state of motion. Researches in biology has allowed us to point out the evidence of a continuous state of motion of the organism: motivation can no longer be limited to a simple reaction to a stimulus. Disagreeing with some behaviourist, theories $[5,6]$ showed that associations are never the cause of the events and therefore that a deed cannot be explained by the association between a stimulus and a behavioral reaction. The way the human body functions is far more complicated: determining what pushes it to react requires a detailed study of a person's aspirations.

According to the references [7,8], several types of motivation exist, which differ from one another by the degree of underlying self-determination in behavior. We can distinguish three different types of motivation: intrinsic, extrinsic and non-motivation.

Intrinsic motivation is subdivided into three subclasses: (1) intrinsic motivation related to stimulation: the high jumper seeks the thrill felt when he lifts off the ground; (2) intrinsic motivation related to accomplishment: the jumper aims to improve his performance with the only purpose of improving his skills; (3) intrinsic motivation related to knowledge: the student discovers new jumping techniques.

So intrinsic motivation reflects the human natural propensity to learn and assimilate [9].

We can also distinguish three types of extrinsic motivation: (1) identified regulation: the student knows that he will obtain a good mark by working in sports class; (2) introjected regulation: the student does not want to train but would feel guilty if he did not try; (3) external regulation: if the student does not train in class, he will be punished.

The concept of non-motivation involves a total lack of motivation. The risk of giving up is then important and can be expressed by missed classes and unjustified exemptions.

Motivation influences a person's behavior by directing him in either a selective or a preferential way towards one kind of practice or another. The engagement in the activity and the giving up thereof will be dictated by motivation. It influences the amount of effort but also the dedication the subject invests in the action and therefore, might influence his progress.

Each individual expresses hypotheses on the possible expectations of his actions and on the valence that it can create. Naturally curious and interested, the willingness to learn of man is not always well exploited by the teachers who most often rely on external incitators such as rewards or sanctions [10, $11]$.

Motivation should be studied either as a correlating variable by examining motivation-related elements that are involved in the process of its development, or as an independent variable, by asking oneself to what extent it contributes to "explaining" the behavior [12]. In our research, we have chosen to study motivation as a correlating variable and a non-explanatory factor of the performance.

The expectations forecasted by the subject as well as the generated valences can influence his motivation. 
For example, materially rewarding a person in case of success might diminish his feeling of self-satisfaction and therefore diminish his future efforts [13]. The fear of failing in front of his classmates may also suppress all active behaviors in the student who doubts his capacities; the student doesn't want to appear incompetent in front of his classmates.

"The student's activity is directed towards, and ruled by, a goal to reach, an aim that is cognitively recognized and makes the subject's needs concrete" [14]. Indeed, the person gives himself a goal to reach that is adapted to the expected results. The commitment will then depend on the perceived difficulty of the task and the extent of the desire to succeed. This forecasting of the result to achieve is therefore the origin of the subject's dedication to the task. Fixing an aim correlated to the relevance of the diagnostic assessment, seems then most important in regulating the behavior. It is for the student an element which contributes to defining a performance project, a goal to reach, an element which both releases motivation and guides the teacher in his choice of a way to start the activity.

According to the reference [15], motivation is characterized by the "process through which personal resources such as time, energy, etc., are granted in preparation for reaching a goal, an object or any result. As an agent of continuous behavior regulation, motivation decides to start or put an end to activity, to change direction or goal, it rules the intensity and the persistence to put in the effort."

A variety of behaviors expressed by direction, intensity, persistence, continuous motivation or performance can allow us to characterize motivation [16-23]. Research in schools [24-29] or sports [17, 22, 30-31] uses accomplishment motivation based on the "theory of goals" as a model [32].

In this context of accomplishment, the subjects are mostly aiming to show their skills $[18,21,22,24,27$, $31,33]$.
There are two types of aims surface: (1) The "mastering aim" [22-24] also described as a "learning aim" [27] or as a "devotion to the task" [28, 31, 33]. The learning, mastering and personal enhancement experiences are then related to success and highlight the subject's progress associated to his capacity to resolve problems on account of efforts. (2) The "competing aim" [22] or "performance aim" [24, 27] or else the "implication of the ego" [28, 31, 33]. Improvement or personal mastering do not relate to success. The subject compares his own results to the others, assesses both performance and amount of effort invested. He positions himself by comparison to his partners.

Therefore the theory of goals allows us to establish a relation between a subject's behavior and the goal he appointed himself. The intensity and the persistence of the individual's action will come from the interaction between the goal he pursues and the skill he reckons he has in this situation $[17,19,22]$. In our study, the theoretical height should then represent the goal to achieve for the student.

\subsection{Self-Fulfilling Prophecies}

In social psychology, the theory of self-fulfilling prophecies designates the impact social expectations have on social reality, "a self-fulfilling prophecy is a definition that at first is wrong but that creates a new behavior that makes that originally false idea true" [34]. A self-fulfilling prophecy occurs when a false belief leads to its own making.

As far as school is concerned, the teacher's belief regarding a student may model him to fit the idea he has of him [34]. It is only when Rosenthal and Jacobson's book "Pygmalion at school" [35] was released that the theme of the teacher's expectations started to be studied.

The student's life is influenced by the self-fulfilling prophecies' dynamic: slow students internalize the idea that the teacher has of them, by withdrawing from school work and by showing hostility towards other 
students. Not only can the student's perception of his teacher's expectations influence his own expectations, but if the other students perceive it, it can also change the quality of the interaction between the students.

Numerous researches have aimed to study the concept of self-fulfilling prophecies [36-38] and point out three stages: (1) the elaboration of the teacher's expectations; (2) the differentiated treatment based on the expectations; (3) the student's reaction according to the initial expectations.

If the first stage is based on relevant indications, the students' results will be predicted rather than influenced by the teacher [39]. Indeed, $80 \%$ of the students' results would be due to a reliable prediction made by the teacher whereas the proportion due to self-fulfilling prophecies would only be $20 \%$ [40].

The diagnostic evaluation provides help in the process of elaborating the teacher's expectations. While helping the student to set himself a goal, this kind of assessment modifies the teacher's action all through the cycle. His input is adapted to the student he is dealing with. Even if the feedback given to the students varies according to the nature of the teacher's expectations, he will have to devise a cycle project that will allow the student to reach the defined goal [41].

The student's analysis of the feedback will affect his sense of competence and his personal efficiency. He will transform the resources that he thinks he possesses into capacity belief or self-esteem. These resources are all the knowledge, aptitudes, body types or affective climates that the subject can use to reach his aim. The will to reach this goal will depend on the value of the task which is constituted of the relation between cost and benefit. The more divergent the teacher's skill expectations are from the student's perception of his own skills, the higher is the risk that the student will refuse to commit to the activity.

His sense of competence and the credit he gives to his instructor play major roles in the learning process.

The teacher must then try to guide his students in setting themselves an optimum goal to reach at the end of the cycle. He will try to offer his students a diagnostic evaluation that is accurate and objective.

\subsection{Forecasting the Sports Performance: High Jump} Example

A great number of studies, mostly issued from Germany or the United States have tried to answer the question of the predictability of the Fosbury-Flop performance [42-44] by studying different field tests in order to examine their relation to the Fosbury-Flop performance. All these researches are based on consensus about the different tests of two feet take-off techniques: they have no forecast value regarding the performance. These tests offer indications on a potential but under no circumstances can they predict a performance.

Concerning the tests for one foot take-off techniques, no consensus has been reached to date. The studies have revealed discordant results. Indeed, in some writers' work, we find correlations between physical ability tests and Fosbury-Flop performance $[43,45,46]$. With other writers, these tests have no forecast value $[44,47]$.

The major pitfall in all these studies is that they endeavored to predict the performance based only on a simple test without taking into account the other aspects responsible for the performance [44, 46]. An alternative to these forecasting models with one variable (simple regression) is to use a model with multiple regressions. Reference [46] is about an analysis of the different anthropometric and physical factors of the performance in the light of those validated by different studies. The population studied was composed of 117 secondary school children and of 120 STAPS/Physical Education students aged between 18 and 20 . The factors that were studied were the height, compass (inside leg measurements) and "skellic" rating (ratio between the size of the legs and the size of the body brought to percentage).

The take-off test that was carried out was a one foot 
take-off after a Fosbury-Flop type run-up (curved). The jumper touches, with the hand opposite his take-off foot, a height gauge that can be attached to a Basket-ball post. The results of this study show that: (1) The anthropometric factor that is most correlated to the performance is height (factor a). Neither the skellic rating nor the compass shows a correlation with the performance. All forms of scales that take into account either of these two factors seems unsuitable to the realities of the components in the Fosbury-Flop performance. (2) The one foot take-off technique presents an important correlation to the performance. It will be revealed by the biggest height reached by the hand (fatter b). (3) Physical ability can be acknowledged by deducting the performance made on the Fosbury-Flop high jump from the sum of the take-off and the leg size. This indicator is positive for a technical level that is above the average, negative for a feeble technical level and equals zero for an average technical level. Factor c ranges from -0.3 (beginner making a Eastern cut-off: by taking off like the scissors, but extending his back and flattening out over the bar) to +0.3 (high level).

Equation (1) is as follows [46]:

$$
Y=-0.618 a+0.898 b+0.669 c-0.08
$$

The forecasting model thus attained allows us to make a significative correlation with the Fosbury-Flop performance, with a type-error of $3 \mathrm{~cm}$. By way of illustration, by applying this equation to Javier Sotomayor's characteristics, the theoretical performance we obtain is of $2.49 \mathrm{~m}$, which is only 4 $\mathrm{cm}$ above his world record.

This forecasted equation of the performance can be used by the sports teacher in order to devise a final assessment for high jump. The calculation of the gap between the theoretical performance and the actual performance on the high jump will determine the student's skill level and therefore allows us to assess the mastering of the execution graded in 5 levels: "1" matches the lowest level, "5" the highest [49]. Once the expected level is set for a form, factor c can be assimilated to a stable figure.

For a class of year ten students having already carried out a cycle of high jump the previous year (2) be as follows:

$$
Y=-0.618 a+0.898 b+0.3
$$

The equation can be submitted to the students at the beginning of the cycle in order to help them, through an objective diagnostic evaluation, to set themselves a precise goal. Indeed, the student knowing his theoretical performance will liken it to his teacher's expectation and will thus shape his own competence perception.

This tool allows us to study the influence of the announcement to a student on his theoretical performance.

For the student, this forecasting of the theoretical performance represents the knowledge of his teacher's expectations concerning him. These expectations will determine his own competence perception and will set the goal to reach.

Our hypothesis will then be as follows: the knowledge of the feasible theoretical performance for high jump will enhance the student's motivation and will therefore influence his learning process. In other words, the student's motivation profile will depend on the performance target that he will have set with the help of the teacher and will therefore influence his progress.

\section{Materials and Methods}

We have offered a cycle of 7 sessions in high jump to two groups hereafter named A and B. Group A had access to the knowledge of their theoretical performance whereas group B did not.

\subsection{Population}

The test group consisted of French secondary school students (ninth-grader), A and B, educated in the same school: the population of the two groups therefore came from similar social backgrounds. All the students carried out a 7 session high jump cycle. 
The average age of the students taken into account in class A is 15.57 years old (sd $<1.43 \%$ female) and the average age of those in class B is 15.66 years old ( $\mathrm{sd}<1.52 \%$ female).

The initial take-off test allows us to know the theoretical performances (Init. Theo. Perf.) for the two groups whereas the test of the high jump gives us their achieved initial performances (Init. Perf). The average initial theoretical performance for group A is $1.33 \mathrm{~m}$ whereas group B's is $1.30 \mathrm{~m}$.

The ANOVA test carried out on the groups does not show any significant effect on the theoretical performance $[\mathrm{F}(1,33)<1]$. These results highlight the absence of physical capacity differences between the subjects selected at the beginning of the cycle.

The average initial performance achieved in Fosbury-Flop of the group with knowledge of their theoretical performance is of $1.26 \mathrm{~m}$ whereas the group without that knowledge has an average of 1.16 $\mathrm{m}$.

The ANOVA test carried out on the groups does not show any significant effect on the theoretical performance $[\mathrm{F}(1.33)=3.21 ; \mathrm{ns}]$. The measurements were not invasive. All the participants received prior information on the protocol and they gave written consent. The study was in compliance with the Helsinki Declaration.

\subsection{Pedagogic Modalities}

The teachers undertook a common preparation of their cycle. The situations offered were identical for both classes. During their first session, the two groups engaged in a high jump competition in which the bar was raised $3 \mathrm{~cm}$ by $3 \mathrm{~cm}$.

The final assessment took place in the same way. The subjects' size and performance at the basket-ball post were noted during the first and the last session of the cycle.

The subjects answered the questionnaire two days after the first session and then three days before the last session.
The instructor of class A kept a copy of the data allowing the calculation of his students' theoretical performance and announced the results during the second session. That group is then referred to as "with knowledge" (Kn). On the other hand, class B's teacher did not keep the data and therefore did not have access to his students' theoretical performance. This is the group "without knowledge" (wKn).

\subsection{Data Collection}

The subject's motivation profile was defined at the beginning and at the end of the cycle. The students answered a questionnaire based on "The scales of motivation in sports" [50].

Reference [51] classes the subcategories of motivation defined earlier (intrinsic: IM; extrinsic: EM and non-motivation: NM) according to self-determination valued from "0" to " 100 " ("100" matching the highest level of self-determination). The use of this scale gives us access to the distribution of each subject's motivation inside each category while calculating his self-determination grade (S.D.G.).

We have kept the order offered, in order to maintain an alternation of the appearance of three types of motivation in our questionnaire. Twelve questions refer to intrinsic motivation; twelve refer to extrinsic motivation and four to non-motivation.

An exploratory collection was carried out on a class $\mathrm{C}$, from the same school but not included into the protocol, so as to test the viability of this questionnaire. We then collected and went through the data concerning motivation of all the subjects in both classes.

During the first and the last sessions in the cycle, both classes carried out a test with the basket-ball post. Their height, related to the maximum height they touched allowed us to determine their feasible theoretical performance at the beginning and at the end of the study.

The results for the first session competition designated each subject's initial performance (Init. 
Perf.), whereas the results for the last session competition designated the final performance (Fin. Perf.)

\subsection{Data Processing}

\subsubsection{Calculation of the Self-Determination Grade}

The answers to the initial and final questionnaires have been entered into a double entry dynamic chart. These questionnaires were composed of 28 questions referring to a particular type of motivation.

We have processed every one of them by differentiating the types of motivation for each subject and by using the code key noted [51]. Each question referred to a specific type of motivation, in other words 7 types of motivations each appearing in 4 distinct questions, we summed up the values assigned to the questions relative to each category.

The following formula allowed us to calculate each subject's self-determination grade (S.D.G) (3) [52]:

$$
\begin{aligned}
& \text { S.D.G. }=\mathrm{IMKn} * 2+\mathrm{IMA} * 2+\mathrm{IMS} * 2+ \\
& \text { EMIdR } * 1+\text { EMInR }^{*}-1+\text { EMER }^{*}-1+ \\
& \mathrm{NM}^{*}-2 \mathrm{Amt} *-2 \text {. }
\end{aligned}
$$

IMKn: intrinsic motivation related to knowledge, IMA intrinsic motivation related to accomplishment, IMS: intrinsic motivation related to stimulation, IdR: identified regulation,

InR: introjected regulation, ER: external regulation, NM: non-motivation, EM: extrinsic motivation.

The S.D.G at the beginning of the cycle (initial S.D.G) in each class was then compared with their S.D.G. at the end of the cycle (final S.D.G.).

\subsubsection{Calculation of Progress}

Each class's progress was worked out from the evolution in performance between the beginning and the end of the cycle (4):

$$
\text { Progress }(\text { Perf })=\text { Fin. Perf. }- \text { Init. Perf. }
$$

The improvement in performance characterizes in this case the student's progress. The development of skills is revealed by the gap between the achieved performance and the theoretical performance (Theo. Perf.). The decrease of this gap expresses the student's evolution in terms of capacity level. Indeed, the more efficient the student's technique is, the higher the achieved performance will be.

Therefore we have calculated (5):

$$
\text { Progress }=(\text { Theo. Fin. Perf. }- \text { Fin. Perf. })-
$$$$
\text { (Theo. Init. Perf. - Init. Perf.) }
$$

This study therefore allows us to analyze the progress in terms of performance but also in terms of capacity level. We conducted an analysis of the repeated measure variance (ANOVA test) pedagogic modalities (inter-group factor) $\mathrm{X}$ learning (intra-group factor). These two variables were systematically tested and so was the interaction pedagogic modality $\mathrm{X}$ learning. The significance threshold was set at $P<$ 0.05 .

\section{Results}

The ANOVA test shows no significant effect either on the theoretical performance $[\mathrm{F}(1,33)<1$; ns], or on the achieved performance $[\mathrm{F}(1,33)=3.21$; ns], or on the gap between these two performances $[F(1,33)=$ $3.80 ; \mathrm{ns}]$ : the two sub-groups are homogenous on these 3 indicators (Tables 1 and 2). The analysis of the initial questionnaires allows us to test the group's homogeneity concerning motivation. The initial S.D.G. (self-determination grade) of the group with knowledge is 76 whereas it drops to 58 for the group without knowledge. However this inter-group gap is not significant $[\mathrm{F}(1,33)=2.28 ; \mathrm{ns}]$.

Table 1 Summary chart of the achieved results.

\begin{tabular}{lllllll}
\hline & \multicolumn{3}{c}{ Initial } & \multicolumn{2}{c}{ Final } & \multicolumn{2}{c}{ Progress } \\
\cline { 2 - 7 } & Kn $(\mathrm{A})$ & wKn $(\mathrm{B})$ & $\mathrm{Kn}(\mathrm{A})$ & $\mathrm{wKn}(\mathrm{B})$ & $\mathrm{Kn}(\mathrm{A})$ & wKn $(\mathrm{B})$ \\
\hline Average/Theo. Perf. (1) & 1.33 & 1.30 & 1.37 & 1.28 & 4 & -2 \\
Average/Perf. (2) & 1.26 & 1.16 & 1.29 & 1.20 & 3 & 4 \\
Avererage/I.A & 76 & 58 & 64 & 36 & -12 & -22 \\
Skill level (1-2) & 7 & 14 & 8 & 8 & 1 & -6 \\
\hline
\end{tabular}


Table 2 ANOVAs of Inter and Intra-group comparison.

\begin{tabular}{lll}
\hline ANOVA $(\mathrm{ddl1}, \mathrm{dd} 2)=(1,33)$ & $\mathrm{F}$ & $P$ \\
\hline Inter-group comparison (with/without cns) & & $\mathrm{n} . \mathrm{s}$ \\
\hline Initial theorical performance (1) & $<1$ & $\mathrm{n} . \mathrm{s}$ \\
Initial performance achieved (2) & 3.21 & $\mathrm{n} . \mathrm{s}$ \\
Initial skill level (1-2) & 3.80 & $\mathrm{n} . \mathrm{s}$ \\
Difference in progress & 2.28 & $\mathrm{n} . \mathrm{s}$ \\
I.A initial & 3.30 & $<0.05$ \\
Final skill level & 4.52 & $<0.001$ \\
I.A final & 5.23 & $<0.001$ \\
Disparity I.A final/initial & 13.74 & $<0.05$ \\
Intrinsic motivation & 4.96 & $<0.05$ \\
\hline Intra-group comparison (initial/final) & & $<0.01$ \\
\hline Progress of the 2 groups & 4.53 & $<0.05$ \\
Intrinsic motivation & 7.92 & \\
\hline Variable interactions (intra/inter-groups) & & \\
\hline Progress & 8.68 & \\
\hline
\end{tabular}

The analysis of the variable made on the learning process also shows a lack of significance on the progress $[\mathrm{F}(1,33)=3.51$; ns $]$. However the ANOVA test expresses a significance on the interaction of these variables $[\mathrm{F}(1,33)=8.68 ; P<0.05]$. The progress achieved in terms of physical capacity development of the subject is therefore superior for the group with knowledge.

The ANOVA test conducted on the pedagogic modalities shows a significance of the progress in terms of skill level $[\mathrm{F}(1,33)=4.52 ; P<0.05]$. The beginning skill level of the two groups is estimated at "2" for all the students (refer to section 1.3). At the end of the cycle, the group without knowledge stayed at a skill level of "2" whereas the group with knowledge reached a skill level of "3" (with no dispersion).

The self-determination grade of the two groups dropped a lot at the end of the cycle. The initial S.D.G for the group with knowledge was of 76 whereas the final S.D.G. is of 64. The initial S.D.G. for the group without knowledge was of 58 whereas the final S.D.G. is of 36. The ANOVA test made on the learning process shows a significance on the performance $[\mathrm{F}(1,33)=5.23 ; P<0.001]$.

The initial self-determination grades for our two groups express a high level of motivation at the beginning of the cycle. The motivation drop at the end of the cycle is limited in the case of the group with knowledge.

The difference between the initial and final S.D.G. expresses the evolution of the subject's motivation during the cycle (Fig. 1). The ANOVA test made on the pedagogic modality shows a significance on the S.D.G. $[\mathrm{F}(1,33)=5.23 ; P<0.001]$ and a significance on the gap between the initial and final S.D.G. $[\mathrm{F}(1,33)$ $=13.74 ; P<0.001]$.

The analysis of the distribution of the motivation profile for each group shows that the intrinsic and extrinsic motivations are more present for the group with knowledge whereas non-motivation is less present (Fig. 2).

The motivation profile of the subjects from the group with knowledge is based more on intrinsic motivations than that of the group without knowledge. The motivation drop concerning both the final extrinsic motivation and final intrinsic motivation for the group with knowledge is less important than that observed for the group without knowledge.

The motivation profile for the two groups is therefore different. The ANOVA test made on the learning process shows a significance on the subject's intrinsic motivation $[\mathrm{F}(1,33)=7.92 ; P<0.01]$. An analysis of the repeated measure variable allows us to 


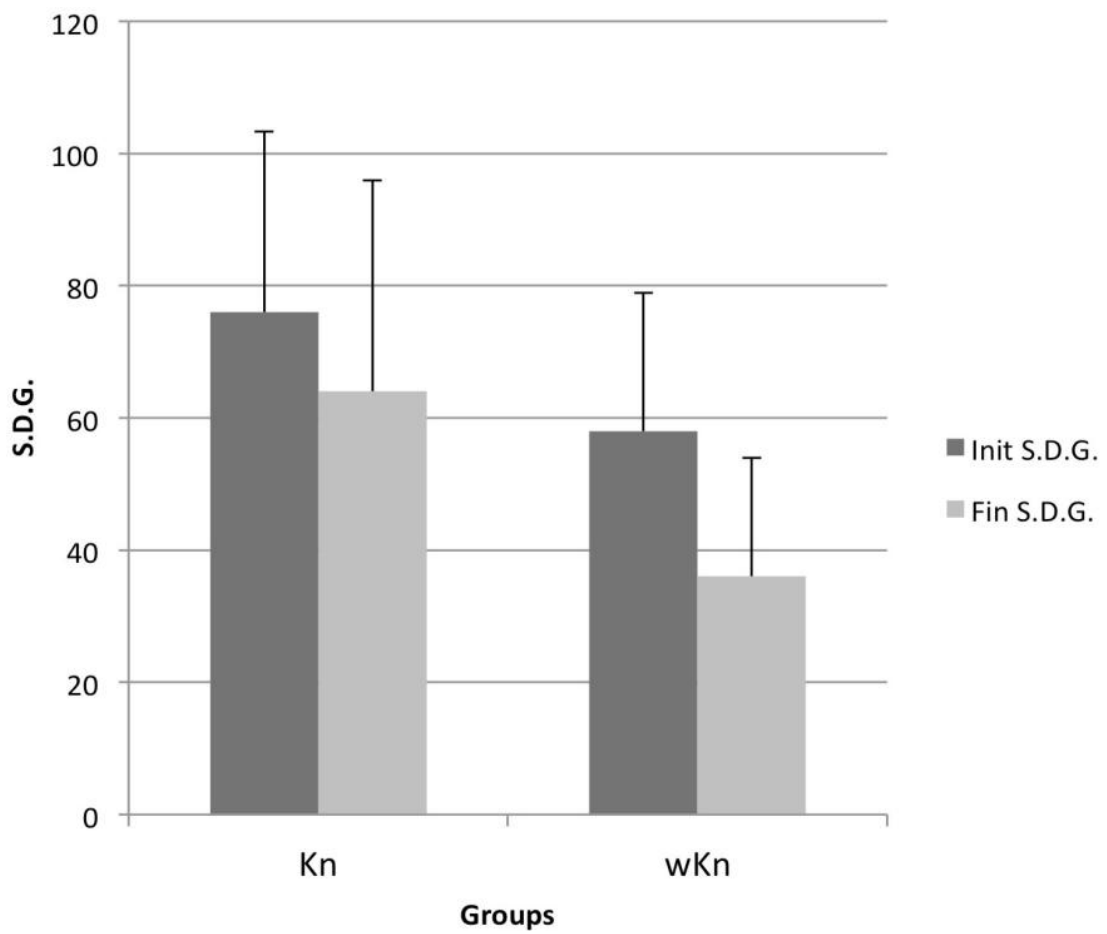

Fig. 1 Comparing the initial and final self-determination grades for the two groups.

Init. S.D.G: initial self-determination; grade Fin. S.D.G: final self-determination grade; "with knowledge": Kn, "without knowledge”: wKn.

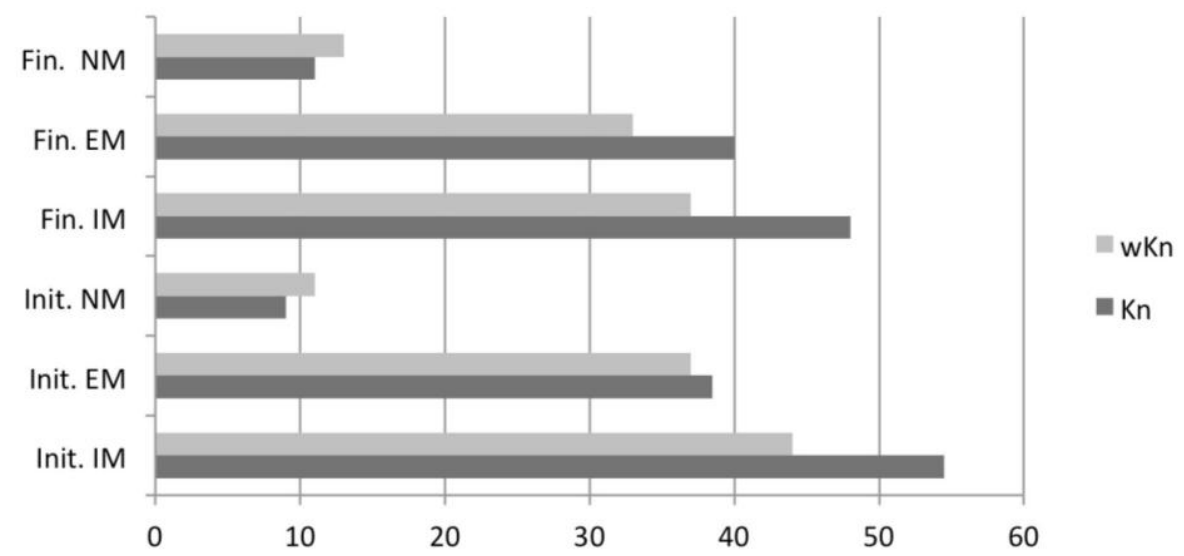

Fig. 2 Characteristics of the initial and final motivation for both groups.
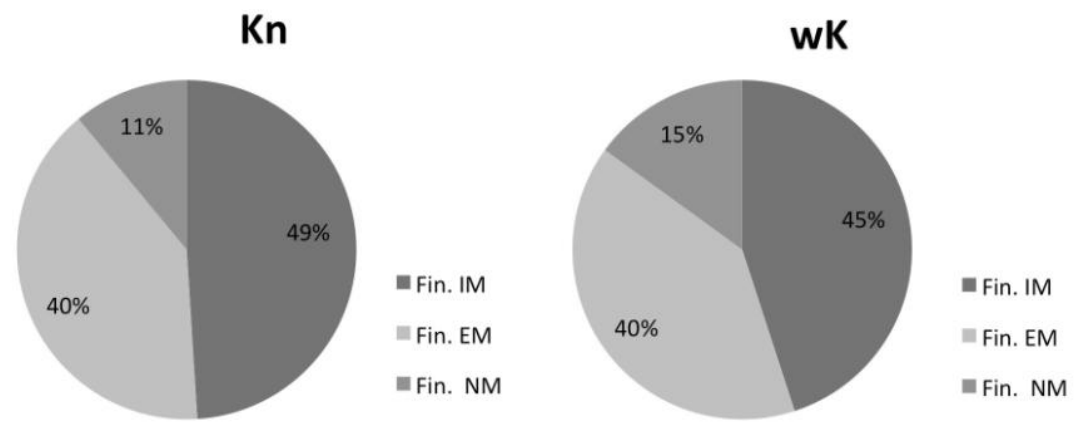

Fig. 3 Final distribution of the two groups' types of motivation.

Legend: Intrinsic motivation: IM; extrinsic motivation: EM and non-motivation: NM, final: Fin. and initial: Init., with knowledge: Kn and without knowledge: wKn. 
notice a significant influence of the pedagogic modal modality of these intrinsic motivations $[\mathrm{F}(1,33)=4.94$; $P<0.05$ ] (Fig. 3).

The pedagogic modality acts in a significant way on the final intrinsic motivations that have a predominant role in the motivation profile of the group with knowledge. The share of extrinsic motivation stays identical for both groups whereas non-motivation is enhanced in the group without knowledge.

\section{Discussion}

The study that involved comparing the initial level of our two groups has shown that they were truly homogenous and comparable not only in terms of initial performance and of theoretical performance but also in terms of the gap between these two performances, which implies a likeness concerning the skill level.

The high S.D.G., with a higher level for the group with knowledge, expresses an important initial motivation for both groups. Our teachers are therefore theoretically facing classes particularly motivated concerning high jump.

Our two groups are as homogenous concerning the theoretical performance as for the initial motivation level.

Progress has been achieved in terms of performance but, contrary to our hypothesis, group B has achieved a progression superior by $1 \mathrm{~cm}$ to that of group A. Although not significant, the difference of initial performance superior by $10 \mathrm{~cm}$ for group A can explain this gap in favor of group B. It is indeed easier to progress when the initial performance is lower whereas the theoretical performance indicates equivalent capacities.

The group without knowledge thus had more room for improvement. The pedagogic modalities did not have a significant impact on the performance but it would have been interesting to study the effects of the variable "pedagogic modalities" over a longer time span. Indeed, a cycle of seven two hours sessions can hardly claim to modify physical behavior sufficiently/significantly in a scale activity like high jump.

Moreover, this activity does not allow a precise measure of the performance since the bar is raised 3 $\mathrm{cm}$ by $3 \mathrm{~cm}$. The student can, for example, achieve a jump in which he clearly clears the bar whereas he would fail for other reasons (psychological or context-related) at the higher level. A $1 \mathrm{~cm}$ difference of progress allows neither refutation nor confirmation of our hypothesis.

The "learning process" variable therefore has an effect on progress whereas the "pedagogic modalities" variable does not seem to have an effect on performance.

Regarding the mastering of the execution, the theoretical performance for the group without knowledge has dropped by $2 \mathrm{~cm}$ whereas that of the group with knowledge has risen by $4 \mathrm{~cm}$. The difference between the theoretical performance at the beginning and at the end of the cycle comes from the work concerning the quality of the impulsion and from an attempt to develop the subject's physical capacities from the two teachers. Indeed muscular reinforcement exercises have been offered to both groups as well as numerous situations that favor the link between the run and the jump. The fact that the group with knowledge has progressed more in terms of theoretical performance can be explained by an implication coming from the subjects in these learning situations.

The initial difference between the theoretical performance and the performance achieved by the group without knowledge has lessened over the duration of the cycle. The progress the later achieved concerning skill is nonetheless to be put into perspective facing the drop of the theoretical performance. Indeed, by comparing this group's initial theoretical performance to their final performance, the difference is of $10 \mathrm{~cm}$ whereas the same difference for the group with knowledge would be of $3 \mathrm{~cm}$. By 
comparing the performance achieved at the end of the cycle with the initial theoretical performance, we obtain the subject's skill level evolution.

This difference between the initial theoretical performance and the achieved final performance matches the aim, for the subjects of the group with knowledge, to reach their initial set goal. The performance achieved by this group can then be likened to the teacher's initial expectations.

The subject's knowledge of the theoretical performance did not lead to a significant progression in terms of pure performance, but the subjects having had access to that knowledge have nevertheless significantly progressed in terms of skill level.

Let us now study the impact of this pedagogic modality on the student's motivation. The two groups had a very strong motivation at the beginning, certainly due to the effect of surprise and novelty [53] that constitutes a change of cycle for the student in sports class (Fig. 1). Besides, with the use of deep foam matting, high jump takes on a ludic connotation. The learning process therefore did not allow the upkeep of this motivation. However the S.D.G. drop concerning the group without knowledge is stronger than that concerning the group with knowledge (Fig. 2).

The intrinsic motivation of the group with knowledge is therefore more important than that of the group without knowledge. According to the strength of the motivation theory, this intrinsic motivation is to be sought in priority by the teacher to enhance the student's commitment to the action: "Personal motivation is one of the best forecasting indicators of the pursuit of a program of exercises" [52]. Two important needs are to be fulfilled to create intrinsic motivation: the subject needs self-determination and a feeling of a high level of capacity. The high level of intrinsic motivation that characterizes the group with knowledge therefore expresses the development of an important feeling of self-determination in its subjects. Indeed, the knowledge of their theoretical performance has guided them in the choice of a precise performance goal. This feeling of self-determination has therefore been influenced by the knowledge of the teacher's expectations. These competence expectations, in terms of performance, have then impacted the subject's perception of competences.

The subjects in both groups have an intrinsic motivation superior to any other type of motivation (Fig. 3) but this motivation lessens less than the others for the group with knowledge during the S.D.G. drop noticed earlier.

The learning process with knowledge of one's theoretical performance therefore limits the S.D.G. drop but also favors a better conservation of the subject's initial intrinsic motivation.

\section{Conclusion}

In our study, the knowledge of the achievable theoretical performance for high jump does not influence the student's performance in a significant way. However, it impacts the learning process in terms of mastering the execution by favoring the setting of a goal for the subject.

The high level of motivation created by the novelty at the beginning of the cycle has very clearly dropped towards the end of the cycle. The knowledge of the teacher's skill expectations limits this motivation collapse. On the other hand, the pedagogic modality also influences the student's motivation profile. Indeed, the intrinsic motivation, which was strong at the beginning of the cycle, decreases less with the subjects who have had access to their theoretical performance. In other words, the student's motivation profile will depend on the performance aim that he will have set himself with the help of his teacher and will therefore influence his progress.

Giving the student a precise aim for high jump therefore benefits his learning in terms of mastering the execution and limits the decline of his motivation during the cycle. The student will then be able to base 
his own competence perceptions on his teacher's expectations. "As soon as his teachers started to treat him as a good student, he truly became so: for people to deserve our trust, we have to start by giving it to them" [54]. Indeed, the teacher takes a risk by assuring his student that if he works seriously, he will be able to pass this or that height. When a student has not reached his goal, does it come from a lack of hard work and dedication or must the teacher's work be re-evaluated? Does the student fail to clear that bar because he doesn't commit totally to the activity or because the teacher did not set the right obstacles and didn't offer adapted learning situations?

The use of the forecasting equation of the performance allows the teacher to offer an objective diagnostic or final evaluation but it also makes the conception of his cycle project easier. Indeed, determining skill levels in the class benefits the creation of groups with homogenous needs. An analysis of the teacher's pedagogic interventions could allow to see the feed-back variations both in quantity and quality depending on the nature of the expectations.

\section{References}

[1] Kerlirzin, Y., Dietrich, G., and Vieilledent, S. 2009. Motor Control. Movement Organisation and Control. Paris: Presses Universitaires de France. (in French)

[2] Dunlap, K. 1932. Habits: Their Making and Unmaking. New York: Liveright.

[3] Kuo, Z. Y. 1937. "Prolegomena to Praxiology." The Journal of Psychology 4 (1): 1-22.

[4] Watson, J. B. 1919. Psychology from the Standpoint of the Behaviorist. Philadelphia: Lippincourt.

[5] Lewin, K. 1922. "The Problem of Free Measure and the Fundamental Law of Association 1." Psychologie Forschung 1: 191-302. (in German)

[6] Lewin, K. 1922. " The Problem of Free Measure and the Fundamental Law of Association 2." Psychologie Forschung 2: 65-140. (in German)

[7] Deci, E. L., and Ryan, R. M. 1985. Intrinsic Motivation and Self-Determination in Human Behavior. New York: Plenum.

[8] Deci, E. L., and Ryan, R. M. 2002. Handbook of Self-Determination Research. Rochester, N: University of Rochester Press.
[9] Ryan, R. M. and Deci, E. L. 2000. "Self-Determination Theory and the Facilitation of Intrinsic Motivation, Social Development, and Well-Being." American Psychologist 55 (1): 68-78.

[10] Ryan, R. M., and Deci, E. L. 2013. "Toward a Social Psychology of Assimilation: Self-Determination Theory in Cognitive Development and Education." In Self-Regulation and Autonomy: Social and Developmental Dimensions of Human Conduct, edited by Sokol, B. W. F., Grouzet, M. E. and Muller, U. Cambridge, England: Cambridge University.

[11] Ryan, R. M., and Weinstein, N. 2009. "Undermining Quality Teaching and Learning: A Self-Determination Theory Perspective on High-Stakes Testing." Theory and Research in Education 7 (2): 224-33.

[12] Ryan, R. M. 1970. Blaming the Victim. New York: Vintage Book.

[13] Deci, E. L. 1975. Intrinsic Motivation. New York: Plenum.

[14] Nuttin, J. 1985. Human Motivation Theory: From the Need to the Action Project. Paris: PUF. (in French)

[15] Sarrazin, P. 1995. "Motivation for Accomplishment in Motor Activities: Highlighting of Process and Variables Affecting the Beliefs Related to the Nature of Motor Ability, the Choice of a Difficulty, Effort Supplied, and Performance." HDR, University of Paris XI Orsay. (in French)

[16] Durand, M. 1987. Child and Sport. Paris: PUF. (in French)

[17] Famose, J. P. 1990. Motor Learning and Task Difficulty. Paris: INSEP. (in French)

[18] Famose, J. P. 1991. "Motor Learning and Problems Resolutions." In Motor Learning, Role of Representation, edited by Famose, J. P., Fleurance, P., and Touchard, Y. Paris: revue EPS. (in French)

[19] Maehr, M. L. 1974. "Culture and Achievement Motivation.” American Psychologist 29 (12): 887-96.

[20] Maehr, M. L. 1984. "Meaning and Motivation: Toward a Theory of Personal Investment." In Research on Motivation in Education, edited by Ames, R. and Ames, C. New York: Academic Press.

[21] Maehr, M. L and Braskamp, L. A. 1986. The Motivation Factor. A Theory of Personal Investment. Lexington: Lexington Books.

[22] Roberts, G. C. 1992. "Motivation in Sport and Exercice: Conceptual Constraints and Convergence." In Motivation in Sport and Exercise, edited by Roberts, G. C. Champaign, IL: Human Kinetics.

[23] Vallerand, R. J., and Thill, E. E. 1993. "Introduction to the Concept of Motiation." In Introduction to the Psychology Motivation, edited by Vallerand, R. J. and Thill, E. E. Laval: France. (in French) 
[24] Ames, C. 1984. "Achievement Attributions and Self-Instructions under Competitive and Individualistic Goal Structures." Journal of Educational Psychology 76 (3): 478-87.

[25] Ames, C. 1992. "Achievement Goals, Motivational Climate, and Motivational Processes." In Motivation in Sport and Exercise, edited by Roberts, G. Champaign, IL: Human Kinetics.

[26] Covington, M. V. 1984. "The Motive for Self-Worth." In Research on Motivation in Education: Student Motivation, edited by Ames, R. and Ames, C. New York: Academic press.

[27] Dweck, C. S. 1986. "Motivational Processes Affecting Learning." American Psychologist 41 (10): 1040-8.

[28] Nicholls, J. G. 1989. "The Competitive Ethos and Democratic Education." Cambridge: Harward University Press.

[29] Thill, E. 1993. "Differentiated and Undifferentiated Conceptions of Skill and Effort According to Age: Effects on Affects and on Self-Handicapping Strategies.” Journal International de Psychology 28: 845-59. (in French)

[30] Brunel, P., and Thill, E. 1993. "Motivation in Sport Context: the Effects of the Goals on Cognition and Behavior." Science et Motricité 19: 43-52.

[31] Duda, J. L. 1992. "Motivation in Sport Settings: a Goal Perspective Approach." In Motivation in Sport and Exercise, edited by Roberts, G. Champaign, IL: Human Kinetics.

[32] Weiner, B. 1990. "History of Motivational Research in Education." Journal of Educational Psychology 82 (4): 616-22.

[33] Nicholls, J. G. 1984. "Achievement Motivation: Conceptions of Ability, Subjective Experience, Task Choice, and Performance." Psychological Review 91 (3): 328-46.

[34] Merton, R. 1948. "The Self-Fulfilling Prophecy." Antioch Review 8 (2): 193-210.

[35] Rosenthal, R., and Jacobson, L. 1968. Pygmalion in the Classroom: Teacher Expectation and Student Intellectual Development. New York: Holt, Rinehart, Winston Edition.

[36] Jussim, L. 1986. "Self-Fulfilling Prophecies: A Theorical and Intergrative Revue." Psychological Review 93 (4): 429-45.

[37] Brophy, J., and Good, T. 1974. Teacher-Student Relationships: Causes and Consequences. New York: Holt; Rinehart; Winston edition.

[38] Darley, J. M., and Fazio, R. H. 1980. "Expectancy-Confirmation Processes Arising in the Social Interaction Sequence.” American Psychologist 35 (10): 867-81.
[39] Jussim, L. 1989. "Teacher Expectations: Self-Fulfilling Prophecies, Perceptual Biases, and Accuracy." Journal of Personality and Social Psychology 57 (3): 469-80.

[40] Jussim, L., and Eccles, S. 1992. "Teacher Expectations II: Construction and Reflection of Student Achievement." Journal of Personality and Social Psychology 63 (6): 947-61.

[41] Bahrami, B., Olsen, K., Bang, D., Roepstorff, A., Rees, G., and Frith, C. 2012. "Together, Slowly but Surely: The Role of Social Interaction and Feedback on the Build-up of Benefit in Collective Decision-Making." Journal of Experimental Psychology: Human Perception and Performance 38 (1): 3-8.

[42] Isaacs, L. D. 1998. "Comparison of the Vertec and just Jump Systems for Measuring Height of Vertical Jump by Young Children." Perceptual and Motor Skills 86 (2): 659-63.

[43] Ginter, K. D. 1979. "Training Accompanying Tests on the Flop for Parking Tung of Training Priorities." Leistungsport 9: 323-30. (in German)

[44] Kuhlow, A. 1977. "Motion Diagnostic Determination Conditional and Techno Motor Power Components with Representatives of Plyometric Disciplinen-A Contribution to the Optimization of the Motor Sports Performance Level in the High Jump for Women." Leistung-sport 7: 405-19. (in German)

[45] Singer, R. N. 1977. "Motivation in Sport." International Journal of Sports Psychology 8: 1-22.

[46] Laffaye, G. 2011. "Fosbury Flop: Predicting Performance with a Three-Variable Model." The Journal of Strength and Conditioning Research 25 (8): 2143-50.

[47] Van Coppenolle, H., Boeths, W., Goris, M., and Van Cafelghem, J. 1983. "The Diagnostic and Prognostic Value of Individual Motor Skills Tests for the Fosbury Flop." Lehre der Leichtathletik 58: 179-83. (in German)

[48] Lee, D. N., Lishman, J. R., and Thomson, J. A. 1982. "Regulation of Gait in Long Jumping." Journal of Experimental Psychology: Human Perception and Performance 8 (3): 448-59.

[49] Laffaye, G., and Laffaye, C. 2004. "Fosbury: Remotivate Students." Education Physique et Sportive Revue EPS 307: 63-8. (in French)

[50] Brière, N. M., Vallerand, R. J., Blais, M. R., and Pelletier, L. G. 1995. "Development and Validation of a Intrinsic, Extrinsic and Amotivation Motivation Measure in Sport: The Motivation Scale in Sports." International Journal of Sport Psychology 26: 465-89. (in French)

[51] Vallerand, R. J. 1997. "Toward a Hierarchical Model of Intrinsic and Extrinsic Motivation." In Advances in Experimental Social Psychology, edited by Zanna, M. P. New York: New York Academic Press.

[52] Vallerand, R. J., Deci, E. L., and Ryan, R. M. 1987. 
"Intrinsic Motivation in Sport." Exercise and Sport Sciences Reviews 15: 389-425.

[53] Berlyne, D. E. 1960. Conflict, Arousal and Curiosity.
New-York: Mac Graw-Hill.

[54] Pagnol, M. 1957. The Glory of My Father. Monte-carlo: Pastorelly. (in French) 